\title{
ANALISIS FAKTOR PRODUKSI ALAT TANGKAP PAYANG DI PELABUHAN PERIKANAN PANTAI CAROCOK TARUSAN KABUPATEN PESISIR SELATAN SUMATERA BARAT
}

\author{
Junaidi M.Affan1, Alvi Rahmahs2 \& Zirvathul Murni3
}

1Fakultas Pertanian Universitas Jabal Ghafur

\author{
2,3Program studi PSP Fakultas Kelautan dan Perikanan Universitas Syiah Kuala
}

\begin{abstract}
Payang is one of fishing gear commonly used by fisherman after lift net at Pelabuhan Perikanan Pantai (PPP) Carocok Tarusan of Pesisir Selatan District. This research aims to describe the catch unit of payang and analyze what factors affect production that produced by Payang. This research used census method by taking data of all Payang fishing gear at PPP Carocok Tarusan. The anlyze used as multiple linear regression and data processing entirely used statistical application SPSS version 22.0 with Enter method. Payang fishing gear at PPP Carocok Tarusan is operated by boat 5 GT and payang construction on left wing (left and right) is 20-25 meters, the net body is 10-20 meters, cod end as the spot for collecting fish catch has 5-8 meters, head rope and ground rope is 100 meters, and selambar strap for drawing fishing gear has 200 meters in lenght. Based on results processed with SPSS were obtained equation of multiple linear regression function on Payang fishing gear at PPP Carocok Tarusan as follow: $\mathrm{Y}=-58.747+11.625 \mathrm{X} 1+4.707 \mathrm{X} 2-13.244 \mathrm{X} 3-1.644 \mathrm{X} 4+5.915 \mathrm{X} 5+23.693 \mathrm{X} 6$. Analysis of t-test showed that production factor of Payang fishing gear which has positive effect on the catch result are the length of trip on fishing (X1), the amount of fuel (X2), and setting (X6).
\end{abstract}

Keywords: Payang, factors of production, regresi berganda, pesisir selatan

\section{PENDAHULUAN}

Kabupaten Pesisir Selatan(Pessel) merupakan salah satu dari 19 kabupaten yang ada di Provinsi Sumatera Barat. Kabupaten ini secara geografis terletak antara $0^{\circ} 59^{\prime}-2^{\circ} 28^{\prime}$ LS dan $100^{\circ} 19^{\prime}-101^{\circ} 18^{\prime} \mathrm{BT}$, dengan luas daerah $5.749 .89 \mathrm{~km}^{2}$ dan garis pantai sepanjang 218 $\mathrm{km}$. Kabupaten Pesisir Selatan memiliki 3 pelabuhan perikanan, di antaranya Pangkalan Pendaratan Ikan (PPI) Surantiah, PPI Kambang, dan Pelabuhan Perikanan Pantai (PPP) Carocok Tarusan.Pelabuhan Perikanan Carocok Tarusan terletak di Desa Ampang Pulai Kecamatan Koto XI Tarusan.

Armada penangkapan yang beroperasi di PPP Carocok Tarusan saat ini sebanyak 151 unit, di antaranya kapal motor 86 unit dan perahu motor 65 unit. Alat tangkap yang digunakan sebanyak 151 unityang terdiri dari alat tangkap bagan 60 unit, payang 45 unit, pancing tonda 20 unit, purse seine 1 unit dan gillnet 25 unit. Jumlah alat tangkap payang di PPP Carocok Tarusan mengalami penurunan pada tahun 2016yaituberjumlah 45 unit yang dari tahun sebelumnya 51 unit (UPTD PPP Carocok Tarusan, 2016).

Penelitian ini bertujuan untuk mendeskripsikan alat tangkap payang di PPP
Carocok Tarusan serta untuk mengetahui pengaruh faktor-faktor produksi unit penangkapan payang terhadap hasil tangkapan.

\section{METODE PENELITIAN}

\section{Lokasi dan Waktu Penelitian}

Penelitian ini dilaksanakan selama bulan Juni - Juli 2017 di Pelabuhan Perikanan Pantai (PPP) Carocok Tarusan Kabupaten Pesisir Selatan, Sumatera Barat.

\section{Metode Penelitian}

Pengambilan data pada penelitian ini dilakukan menggunakan metode sensus. Menurut Subana dan Sudrajad (2001), sensus adalah pengambilan data dari populasi dengan cara mengambil seluruhanggota populasi untuk diambil datanya, sehingga didapatkan sampel sebanyak45 unit alat tangkap payang yang ada di PPP Carocok Tarusan.Jenis data yang digunakan yaitu berupa data primer dan data sekunder.

Data primer berupa informasi tentang alat tangkap payang yang terdapat di PPP Carocok Tarusan seperti jumlah armada, jumlah alat tangkap payang, jumlah BBM, jumlah ABK, lama trip penangkapan, jumlah produksi per trip, panjang kantong alat tangkap, panjang sayap 
alat tangkap, jumlah settingalat tangkap per trip, serta kendala yang dihadapi ABK selama melakukan penangkapan di laut. Data sekunder yang digunakan dalam penelitian ini berupa laporan tahunan yang diperoleh dari pihak UPTD PPP Carocok Tarusan serta dilakukan wawancara mendalam terhadap pihak UPTD PPP Carocok Tarusan tentang perkembangan alat tangkap dan armada yang ada serta jumlah produksi yang dihasilkan oleh alat tangkap payang.

\section{Analisis Data}

Analisis data yang dilakukan dalam penelitian ini diolah menggunakan Model Analisis Regresi Linear Berganda dimana terdapat sejumlah variabel bebas yang dihubungkan dengan variabel terikat (tidak bebas). Jika variabel bebas dalam penelitian ini adalah $\mathrm{X} 1, \mathrm{X} 2, \quad \mathrm{X} 3, \ldots, \quad \mathrm{X} 6$ dan variabel terikatnya $\mathrm{Y}$ maka bentuk/rumus umum dari Regresi Berganda adalah sebagai berikut (Simamora, 2005):

$\mathrm{Y}=\mathrm{a}+\mathrm{b} 1 \mathrm{X} 1+\mathrm{b} 2 \mathrm{X} 2+\mathrm{b} 3 \mathrm{X} 3+\mathrm{b} 4 \mathrm{X} 4+\mathrm{b} 5 \mathrm{X} 5+\mathrm{b} 6 \mathrm{X} 6$ dimana:

$\begin{array}{ll}\mathrm{Y} & =\text { Hasil tangkapan }(\mathrm{kg}) \\ \mathrm{X} 1 \mathrm{~s} / \mathrm{d} \text { X6 } & =\text { Faktor Produksi } \\ \mathrm{a} & =\text { Konstanta (intercept) } \\ \mathrm{b} 1 \mathrm{~s} / \mathrm{d} \mathrm{b} 6 & =\text { Koefisien regresi tiap-tiap } \\ \text { faktor produksi } & \end{array}$

Langkah-langkah analisis regresi linear berganda dilakukan untuk menguji keeratan hubungan antara variabel bebas $(\mathrm{X} 1, \mathrm{X} 2, \mathrm{X} 3, \ldots$, X6) dengan variabel terikat (Y). Koefisien Determinasi (R2) untuk menguji pengaruh variabel bebas $(\mathrm{X} 1, \mathrm{X} 2, \mathrm{X} 3, \ldots, \mathrm{X} 6)$ secara serempaksimultan terhadap variabel terikat $(\mathrm{Y})$. Analisis data secara keseluruhan dilakukan menggunakan program aplikasi Statistik SPSS Versi 22.0 dengan metode Enter.

Pengujian terhadap hubungan faktorfaktor produksi alat tangkap payang yang diuraikan dalam persamaan regresi dilakukan dengan cara berikut:

Uji statistika tentang pengaruh faktorfaktor produksi secara bersama-sama terhadap hasil tangkapan (Y) adalah sebagai berikut (Sudjana, 2002):

$\mathrm{F}=(\mathrm{JKreg} / /$ " k)/"JKres/ (n-k-1)"

Dimana :

JKreg = Jumlah kuadrat regresi

JKres = Jumlah kuadrat residual error

$\mathrm{k}=$ Jumlah variabel bebas $\mathrm{n} \quad$ = Banyaknya sampel

Pengujian pengaruh masih-masing faktor produksi terhadap hasil tangkapan (Y), menggunakan Uji $\mathrm{t}$ dengan rumus sebagai berikut (Simamora, 2005):

$\mathrm{t}=\mathrm{b} \_\mathrm{i} / \mathrm{S} \_$bi

Dimana :

bi $\quad=$ Koefesien b ke-i

Sbi $=$ Standar eror koefesien $\mathrm{b}$ ke- $\mathrm{i}$

Variabel-variabel

yang

didugaberpengaruh dalam keberhasilan operasi pada alat tangkap payang adalah sebagai berikut:

Variabel tak bebas : Hasil tangkapan (Y)

Hasil tangkapan (Y), adalah besarnya hasil dari usaha penangkapan payang yang diperoleh nelayan berupa ikan $(\mathrm{kg})$ dalam satu kali trip

\section{Variabel bebas:}

1) Lama trip penangkapan (X1), adalah semakin lama melakukan trip penangkapan (jam) dapat diasumsikan bahwa hasil tangkapan yang diperoleh akan semakin banyak;

2) Jumlah BBM (X2), adalah jumlah bahan bakar yang digunakan oleh nelayan untuk melaut, dinyatakan dalam liter. BBM mempengaruhi jauh dekatnya daerah penangkapan ikan dan lama pengoperasian payang;

3) Jumlah ABK (X3), adalah orang yang ikut dalam pengoperasian payang. Pehitungan jumlah ABK didasarkan pada banyaknya jumlah orang yang ikut dalam kegiatan penangkapan payang per satu kali trip;

4) Panjang sayap (X4), berfungsi untuk menakut-nakuti ikan sehingga mempersempit ruang gerak ikan menuju kantong. Panjang sayap diukur dalam satuan meter;

5) Panjang kantong payang (X5), adalah tempat pengumpul hasil tangkapan yang ditangkap, diartikan bahwa semakin besar kantong payang maka semakin banyak ikan yang dihasilkan;

6) Setting (X6), adalah penebaran jaring payang dalam kegiatan penangkapan/trip. Semakin banyak dilakukan setting, maka bisa diasumsikan hasil tangkapan akan semakin banyak. 
HASIL DAN PEMBAHASAN

Karakteristik Unit Penangkapan Payang di PPP Carocok Tarusan

1. Kapal/perahu paying

Alat tangkap payang di PPP Carocok Tarusan dioperasikan menggunakan kapal/perahu yang sederhana dan tradisional dengan ukuran 5 GT. Kapal/perahu payang tersebut memiliki dimensi panjang12 meter, lebar 2.5 meter, tinggi 1 meter dan kapasitas muatan sebesar 3-5 ton.

\section{Alat tangkap payang}

Alat tangkap payang yang ada di PPP Carocok Tarusan memiliki panjang rata-rata berkisar antara 300-400 meter.Pada umumnya, kontruksi alat tangkap payang yang ada di PPP Carocok Tarusan hampir sama dengan alat tangkap payang yang ada di daerah lain, hanya saja perbedaan nya terletak pada ukuran jaring dan bahan-bahan alat tangkap payang tersebut, bahkan nelayan yang berada dalam satu daerah pun menggunakan ukuran yang tidak sama. Misalnya, payang di PPP Carocok Tarusan mempunyai ukuran panjang kantong dan panjang sayap yang berbeda.

Payang terbuat dari bahan jaring yang terdiri dari bagian sayap (kiri dan kanan), badan, kantong, tali ris (atas dan bawah), tali selembar untuk menarik alattangkap, pelampung dan pemberat. Ukuran setiap bagian jaring pada payang berbeda-beda, seperti bagian kantong yang mempunyai ukuran mata jaring (mesh size) yang paling kecil dikarenakan kantong berfungsi untuk tempat berkumpulnya hasil tangkapan yang terjaring. Berdasarkan penelitian yang dilakukan oleh Gumilang (2010), alat tangkap payang di Desa Bandengan Kabupaten Cirebon memiliki dua buah sayap yang terletak di sebelah kanan dan sebelah kiri yang mempunyai panjang sekitar 100-200 m, bagian badan sepanjang 36-65 m dan kantong terletak di bagian paling belakang jaring yang merupakan tempat berkumpulnya hasil tangkapan adalah sepanjang 10-20 m.

Ciri khas alat tangkap payang di PPP Carocok Tarusan terdapat pada bagian pelampung, yaitu bahan pelampung tanda yang digunakan berasal dari barang bekas (derigen oli) dan bahan pelampung tanda berasal dari sandal jepit yang dibentuk sedemikian rupa agar bisa digunakan sebagai pelampung. Nelayan memilih pelampung berbahan barang bekas (derigen oli dan sandal jepit) dikarenakan teksturnya yang mudah mengapung, gampang dicari dan menghemat pengeluaran. Hal ini

berbeda dengan hasil penelitian yang dilakukan oleh Asriyanto et al., (2013) yang menyebutkan bahwa pelampung tanda pada alat tangkap terbuat dari bahan stereofoam yang dilengkapi dengan bendera, sedangkan pelampung utama terbuat dari bahan PVC (polyvinyl chloridae) yang berbentuk seperti bola. Spesifikasi unit penangkapan payang di PPP Carocok Tarusan dapat dilihat pada Tabel 1 berikut ini:

Tabel 1. Spesifikasi Unit Penangkapan Payang di PPP Carocok Tarusan

\begin{tabular}{lll}
\hline No. & Parameter & Keterangan \\
\hline 1 & Kapal & \\
& - Ukuran kapal (GT) & 5 GT \\
& - Merk mesin & Yamaha \\
& - Tenaga penggerak & 40 PK \\
2 & Alat Tangkap Payang & \\
& - Panjang sayap & $20-25$ meter \\
& - Panjang badan & $10-20$ meter \\
& - Panjang kantong & $5-8$ meter \\
& - Panjang tali ris & 100 meter \\
& - Panjang tali & 200 meter \\
3 & $\quad$ selembar & $8-10$ orang \\
4 & Nelayan (ABK) & \\
& Alat Bantu Penangkapan & \\
& - Pelampung & Gabus/ busa \\
& - Pemberat & Timah \\
\hline
\end{tabular}

Jenis ikan yang menjadi target penangkapan alat tangkap payang ini yaitu ikan pelagis (ikan yang hidup di atas permukaan perairan). Adapun hasil tangkapan yang tertangkap pada bulan penelitian di PPP Carocok Tarusan dapat dilihat pada tabel 2 sebagai berikut.

Tabel 2. Jenis hasil tangkapan yang didapatkan pada bulan Juni-Juli 2017

\begin{tabular}{cclcl}
\hline No & Jenis Ikan & Nama Ilmiah & $\begin{array}{l}\text { Jumlah } \\
(\mathrm{kg})\end{array}$ & $\begin{array}{l}\text { Perse } \\
\text { ntase } \\
\%\end{array}$ \\
\hline 1 & Teri & $\begin{array}{l}\text { Stolephorus } \\
\text { sp. } \\
\text { Euthynus } \\
\text { affiniss }\end{array}$ & 121.500 & 24.5 \\
2 & Tongkol & 101.250 & 20.4 \\
3 & Cakalang & $\begin{array}{l}\text { Katsuwonus } \\
\text { pelamis }\end{array}$ & 67.500 & 13.6 \\
4 & Tenggiri & $\begin{array}{l}\text { Scomberomo } \\
\text { roni } \\
5\end{array}$ & 54.000 & 10.9 \\
6 & Maco & $\begin{array}{l}\text { Seutor } \\
\text { ruconius } \\
\text { Spratelloides } \\
\text { gracilis }\end{array}$ & 10.800 & 2.2 \\
& & & 17.5 &
\end{tabular}




\begin{tabular}{|c|c|c|c|c|}
\hline 7 & $\begin{array}{l}\text { Ekor } \\
\text { kuning }\end{array}$ & $\begin{array}{l}\text { Caesio } \\
\text { cunning }\end{array}$ & 6.750 & 1.4 \\
\hline 8 & Kembung & $\begin{array}{l}\text { Selaroides } \\
\text { leptolepis }\end{array}$ & 47.250 & 9.5 \\
\hline & Jumlah & & $\begin{array}{l}496.050 \\
\mathrm{~kg}\end{array}$ & $\begin{array}{l}100 \\
\%\end{array}$ \\
\hline
\end{tabular}

Berdasarkan tabel diatas, jenis hasil tangkapan alat tangkap payang yang mendominasi pada bulan penelitian adalah ikan teri sebesar $24.5 \%$, ikan tongkol $20.4 \%$ dan ikan tamban sebesar $17.5 \%$.

Berdasarkan hasil wawancara dan pengamatan langsung dilapangan nelayan setempat mengatakan bahwa target utama penangkapan alat tangkap payang ini yaitu ikan pelagis dan ikan yang mempunyai nilai ekonomis tinggi seperti ikan teri (Stolephorus sp.). ikan teri selain mempunyai nilai ekonomis yang tinggi ikan tersebut juga dapat diolah menjadi ikan asin. Hasil tangkapan lainnya yaitu ikan maco (Secutor ruconius), ikan kembung (Selaroides leptolepis), ikan ekor kuning (Caesio cunning), ikan cakalang (Katsuwonus pelamis), ikan tenggiri (Scomberomoroni), ikan tamban (Spratelloides gracilis) dan ikan tongkol (Euthynus affiniss).

\section{Pengaruh Faktor Produksi Terhadap Hasil Tangkapan}

Hasil tangkapan pada alat tangkap payang banyak dipengaruhi oleh faktor-faktor produksi usaha perikanan. Faktor- faktor produksi yang diduga berpengaruh terhadap hasil tangkapan payang di PPP Carocok Tarusan ada 6 variabel di antaranya adalah lama trip penangkapan (jam), jumlah BBM (liter), jumlah ABK (orang), panjang sayap $(\mathrm{m})$, panjang kantong $(\mathrm{m})$ dan jumlah setting (kali).

a. Analisis faktor produksi (Regresi linier berganda)

Besar persentase variabel bebas (X) terhadap variabel terikat (Y) dapat diketahui dari nilai Koefisien Determinasi (R2). Dari tabel output SPSS dapat dilihat bahwa nilai R-Square (R2)dari model regresi yang terbentuk dalam penelitian ini adalah sebesar 0.853 yang menunjukan bahwa kemampuan variabel terikat dalam menjelaskan variabel bebas adalah sebesar $85,3 \%$, sisanya sebesar $14,7 \%$ dijelaskan oleh variabel lain yang tidak termasuk dalam penelitian ini. Variabel lain diantaranya ukuran kapal, faktor lingkungan atau faktor alam seperti musim penangkapan dan cuaca.

b. Uji statistika secara simultan (Uji F)

Hasil analisis secara bersama-sama (simultan) dengan Uji Fdapat diartikan bahwa secara simultan variabel bebas (X) memiliki pengaruh yang signifikan terhadap variabel terikat (Y). Hal ini dibuktikan dari nilai Fhitung sebesar 36.674dan Ftabel sebesar 2.46 yang berarti bahwa Fhitung> Ftabel, maka H0 ditolak. Hal ini juga dapat dilihat dengan besarnya nilai probabilitas 0.000 yang berarti lebih kecil dari pada tingkat signifikasi yang digunakan yaitu 0.05 (Sig. < 0,05) maka dapat disimpulkan bahwa semua faktor produksi atau variabel bebas(X1, X2, X3, X4, X5, dan X6) secara simultan berpengaruh signifikan terhadap variabel terikat (Y). Hal ini dapat pula dikatakan bahwaterdapat pengaruh secara signifikan antaralama trip penangkapan (X1), jumlah BBM (X2), jumlah ABK (X3), panjang sayap (X4), panjang kantong (X5) dansetting (X6) secara bersama-sama terhadap terhadap hasil tangkapan (Y). Jadi dari hasil penelitian ini dapat disimpulkan bahwa variabel bebassecara bersama-sama berpengaruh terhadap hasil tangkapan (Y) pada alat tangkap payang.

c. Uji statistik secara parsial (Uji t)

Pengujian pengaruh masing-masing faktor terhadap produksi alat tangkap payang dilakukan dengan menggunakan program aplikasi statistik SPSS versi 22.0 dengan metode Enter yang memasukkan semua prediktor kedalam analisis sekaligus. Berdasarkan output hasil pengolahan data dalam uji t didapatkan hasil pada Tabel 3 berikut ini.

Tabel 3. Nilai koefisien regresi (bi), nilai thitung dan Sig. alat tangkap payang di PPP Carocok

Tarusan

Coefficients $^{\mathrm{a}}$

\begin{tabular}{|c|r|r|r|}
\hline & $\begin{array}{c}\text { Koefisien } \\
\text { regresi (bi) }\end{array}$ & \multicolumn{1}{|c|}{$\mathrm{t}$} & \multicolumn{1}{|c|}{ Sig. } \\
\hline 1 Constant) & -58.747 & -.521 & .606 \\
X1 & 11.625 & 2.287 & .028 \\
X2 & 4.707 & 3.335 & .002 \\
X3 & -13.244 & -1.277 & .209 \\
X4 & -1.644 & -.906 & .371 \\
X5 & 5.915 & 1.431 & .161 \\
X6 & 23.693 & 4.868 & .000 \\
\hline
\end{tabular}

Keterangan: $\alpha=5 \%(0.05)$

$$
t_{\text {tabel }}=1.685
$$

Hasil pengujian secara parsial pada tabel tersebut dengan nilai ttabel $=1.685$ dapat dilihat pada tabel statistik dengan nilai signifikansi $\alpha=$ $5 \%$ (0.05) bahwa variabel lama trip 
penangkapan (X1), jumlah BBM (X2) dan setting (X6) memberikan pengaruh secara positif dan signifikan terhadap hasil tangkapanpada alat tangkap payang dengan selang kepercayaan 95\%. Berdasarkan Tabel di atas diperoleh bentuk persamaan fungsi regresi linier berganda pada alat tangkap payang di PPP Carocok Tarusan sebagai berikut:

$\mathrm{Y}=\quad-58.747+11.625 \mathrm{X} 1+4.707 \mathrm{X} 2-13.244 \mathrm{X} 3-$ 1.644X4+5.915X5+23.693X6

Dari persamaan tersebut terlihat bahwa variabel lama trip penangkapan (X1), jumlah BBM (X2), panjang kantong (X5) dan setting (X6) mempunyai nilai koefisien regresi positif terhadap hasil tangkapan (Y). Sedangkan jumlah ABK (X3) dan panjang sayap (X4) mempunyai nilai koefisien regresi yang negatif. Nilai positif pada koefisien regresi dapat diartikan bahwa penambahan 1 satuan dari variabel $\mathrm{X}$ akan menaikkan nilai $\mathrm{Y}$ sebesar bi, sedangkan nilai negatif apabila dilakukan penambahan 1 satuan dari variabel $\mathrm{X}$ maka nilai $\mathrm{Y}$ akan turun sebesar bi(Aprilla, 2014).

Nilai b1 $=11.625$ (positif) menyatakan bahwa variabel lama trip penangkapan (X1) berpengaruh positif terhadap nilai variabel terikat $\mathrm{Y}$, sehingga hasil tangkapan payang dipengaruhi oleh lama trip penangkapan. Setiap perubahan atau penambahan lama trip penangkapan (X1) selama satu jam maka hasil tangkapan (Y) akan meningkat sebesar 11.625 $\mathrm{kg}$.

Nilai b2 $=4.707$ (positif) menunjukkan bahwa penggunaan jumlah BBM (X2) dapat mempengaruhi hasil tangkapan payang. Karena, setiap penambahan jumlah BBM sebanyak satu liter maka hasil tangkapan (Y) akan meningkat sebesar $4.707 \mathrm{~kg}$.

Nilai b5 $=5.915$ (positif) menyatakan bahwa hasil tangkapan payang dipengaruhi oleh panjang kantong (X5). Dapat diartikan apabila setiap penambahan satu meter panjang kantong payang maka hasil tangkapan akan meningkat sebesar $5.915 \mathrm{~kg}$. Hal ini dikarenakan semakin panjang kantong maka semakin luas cakupan daerah yang terbentuk, sehingga semakin banyak hasil tangkapan yang akan tertangkap. Hasil di lapangan menunjukkan bahwa panjang kantong payang mempunyai ukuran 5-8 meter, penetapan ukuran panjang kantong ditentukan oleh pemilik alat tangkap dan kearifan lokal tersebut.

Nilai b6 $=23.693$ (positif) menunjukkan bahwa produksi hasil tangkapan payang dipengaruhi oleh jumlah setting(X6) yang dilakukan oleh nelayan. Hal ini dapat diartikan bahwa setiap penambahan jumlah setting sebanyak satu kali dalam trip/hari maka hasil tangkapan payang akan meningkat sebesar $23.693 \mathrm{~kg}$.

Berdasarkan uraian dari masing-masing faktor produksi menunjukkan bahwa lama trip penangkapan (X1), jumlah BBM (X2), panjang kantong (X5) dansetting (X6) menunjukkan hasil regresi yang positif terhadap hasil tangkapan (Y). Penambahan faktor-faktor produksi tersebut akan dapat meningkatkan hasil tangkapan dan begitu juga sebaliknya jika dilakukan pengurangan terhadap faktor-faktor ini akan menyebabkan hasil tangkapan pada alat tangkap payang tidak akan meningkat. Akan tetapi, dari ke empat faktor produksi tersebut, hanya lama trip penangkapan (X1), jumlah BBM (X2) dan setting (X6) yang mempunyai pengaruh positif secara signifikan terhadap hasil tangkapan (Y). Hal ini dapat dibuktikan dari nilai thitung ketiga faktor tersebut besar dari ttabel dan nilai Sig. < 0,05. Berdasarkan hasil penelitian yang pernah dilakukan oleh Rachman et al. (2013) bahwa faktor produksi yang berpengaruh nyata pada alat tangkap payang yaitu pengalaman menjadi nelayan, jumlah trip penangkapan dan panjang kantong.

Nilai b3 $=-13.244$ (negatif) menunjukkan bahwa jumlah ABK (X3) dalam kegiatan pengoperasian alat tangkap payang sangat mempengaruhi hasil tangkapan (Y). Dimana dengan penambahan jumlah ABK sebanyak satu orang dalam kegiatanpenangkapan ikan trip/hari maka, hasil tangkapan tidak akan bertambah sebesar $13.244 \mathrm{~kg}$.

Nilai b4 $=-1.644$ (negatif) menunjukkan bahwa panjang sayap (X4) mempengaruhi hasil tangkapan pada alat tangkap payang. Hal ini berarti bahwa setiap penambahan satu meter panjang sayap pada alat tangkap payang, tidak meningkatkan hasil tangkapan sebesar $1.644 \mathrm{~kg}$. Uraian di atas menunjukkan bahwa variabel jumlah ABK (X3) dan panjang sayap (X4) mempunyai nilai koefisien regresi yang negatif. Dengan kata lain penggunaan faktor-faktor tersebut dalam melakukan usaha penangkapan sudah berlebih, sehingga dapat diartikan bahwa penambahan faktor tersebut bisa mempengaruhi hasil tangkapan. Berdasarkan hasil pada perhitungan uji t, faktor produksi jumlah $\mathrm{ABK}$ (X3), panjang sayap (X4) dan panjang kantong (X5) tidak mempunyai pengaruh yang signifikan terhadap hasil tangkapan (Y) dikarenakan thitung $<$ ttabel dan nilai Sig. $>0,05$. Hasil ini 
sesuai dengan penelitian yang pernah dilakukan Irnawati (2004) yang menyatakan bahwa jumlah nelayan (ABK), panjang sayap dan panjang kantong tidak memberikan pengaruh positif dan tidak signifikan terhadap hasil tangkapan. Namun, dalam pengujian yang dilakukan secara simultan (uji F) semua variabel bebas (X1, X2, $\mathrm{X} 3, \ldots, \mathrm{X} 6)$ memiliki pengaruh yang signifikan. Hal ini dibuktikan dari nilai Fhitung $>$ Ftabel dan Sig. $0,000<0,05$ yang dapat disimpulkan bahwa secara simultan lama trip penangkapan, jumlah $\mathrm{BBM}$, jumlah $\mathrm{ABK}$, panjang sayap, panjang kantong dan setting memiliki pengaruh nyata terhadap hasil tangkapan. Banyak faktor yang berpengaruh terhadap tidak signifikannya suatu model regresi, di antaranya adalah jumlah data (n) yang belum cukup untuk menjelaskan bentuk hubungan dalam suatu model regresi (Ghozali, 2009).

\section{KESIMPULAN}

1. Alat tangkap payang di PPP Carocok Tarusandioperasikan dengan kapal berukuran 5GT dengan jumlah nelayan sebanyak 8-10 orang. Kontruksi payang terdiri dari sayap (kiri dan kanan) dengan panjang 20-25 meter, badan jaring 10-20 meter, kantong 5-8 meter, tali ris (atas dan bawah) 100 meter, dan tali selambar yang berfungsi untuk menarik alat tangkap sepanjang 200 meter. Pelampung dan pemberat pada alat tangkap payang ini terletak pada bagian tali ris atas dan tali ris bawah.

2. Semua faktor produksi atau variabel bebas(X1, X2, X3, X4, X5, dan X6) secara simultan berpengaruh signifikan terhadap variabel terikat (Y).Berdasarkan hasil penelitian didapatkan model regresi dengan persamaan $\mathrm{Y}=-58.747+11.625 \mathrm{X} 1$ + 4.707X2- 13.244X3 - 1.644X4+ $5.915 X 5+23.693 X 6$. Pengujian yang dilakukan dengan uji t, dapat diketahui faktor produksi alat tangkap payang yang berpengaruh positif dan signifikan terhadap hasil tangkapan adalah lama trip penangkapan (X1), jumlah BBM (X2), dan setting $(\mathrm{X} 6)$.

\section{DAFTAR PUSTAKA}

Aprilla, Ratna Mutia. 2014. Analisis Efisiensi Unit Penangkapan Pukat Cincin di Pelabuhan Perikanan Pantai Lampulo Banda Aceh. Tesis. Sekolah Parcasarjana Institut Pertanian Bogor. Bogor.
Bilson Simamora. 2005. Analisis Multivariat Pemasaran. PT Gramedia Puustaka Umum. Jakarta.

Ghozali, Imam. 2009. Aplikasi Analisis Multivariate dengan Program SPSS. Penerbit: Universitas Diponegoro.

Gumilang, Andi Perdana. 2010. Tingkat Pendapatan Usaha Penangkapan Ikan Akibat Kenaikan Harga BBM Pada Nelayan Payang Di PPI Bandengan Kecamatan Mandu Kabupaten Cirebon. Institut Pertanian Bogor. Bogor.

Irnawati, S. 2004. Analisis Aspek Bio-Teknis Unit Penangkapan Payang di Perairan Ulak Karang, Sumatera Barat. Skripsi. Institut Pertanian Bogor. Bogor.

Ismail, Bambang Argo dan Asriyanto. 2013. Analisis Faktor Produksi Hasil Tangkapan Alat Tangkap Centrang Di Pangkalan Pendaratan Ikan Bulu Kabupaten Tuban. Jurnal of Fisheries Resources Utilization Management and Technology Vol 2, No 4: 50-58.

M. Subana dan Sudrajad. 2001. Dasar-Dasar Penelitian Ilmiah. CV Pusataka Setia. Bandung.

[PPP] Pelabuhan Perikanan Pantai Carocok Tarusan. 2016. Buku Tahunan Pelabuhan Perikanan Pantai Carocok Tarusan. Kabupaten Pesisir Selatan: Pesisir Selatan.

Prof. DR. Sudjana, M.A, M.Sc. 2006. Metoda Statistika, Edisi 6. Penerbit Tarsito. Bandung.

Rachman, S., P. Purwanti dan M. Primyastanto. 2013. Analisis Faktor Produksi dan Kelayakan Usaha Alat Tangkap Payang di Gili Ketapang Kabupaten Probolinggo Jawa Timur. Jurnal ECSOFiM. 1 (1) : 69-81. 